\title{
Follow-up Study on the Use of Leg Braces Issued to Spinal Cord Injury Patients $\star$
}

\author{
C. Hong, MD, E. B. San Luis, MD, S. Chung, RPT \\ University of California, Irvine Medical Center, Orange, California, USA, Veterans \\ Administration Medical Center, Long Beach, California, USA.
}

\begin{abstract}
Summary
A letter questionnaire was sent to 250 spinal cord injury (SCI) patients with leg braces who were admitted to a VA Medical Centre from Fanuary 1978 to December 1984. There were 73 responses deemed to be complete and acceptable. Among these 73 patients, 61 were paraplegic at the thoracic level and 12 were paraplegic at the lumbar level. They were all male veterans with an average age of 53.4 years. We found only 16 patients (22\%) who were still using their braces for ambulation at the time of the survey. All 16 had lesions below T9 level, and 13 had incomplete cord lesions. The remaining 57 (78\%) patients were not ambulatory; 13 of these were occasionally using their braces for standing. Statistical analysis revealed that discontinued usage of braces for ambulation was not related to length of initial hospitalisation, years after injury, marital status, educational level, living arrangements, social activities, sports participation or length of initial hospitalisation; but was related to age, level and severity of injury, medical problems and dependency on activities of daily living. In view of similar experiences at other SCI centres, it is concluded that the above factors should be considered in prescribing lower extremity braces for SCI patients.
\end{abstract}

Key words: Spinal cord injuries; Orthotic devices; Lower extremity braces.

Spinal cord injury (SCI) patients have been reported to be successful in ambulation with leg braces (Abramson, 1949; Dinken, 1951; Edberg, 1967; Hussey and Stauffer, 1973; Kent, 1958; Long and Lawton, 1955; Munro, 1951, 1954; Nativig and McAdam, 1978). However, they also have a high frequency of non-usage of issued leg braces for ambulation after discharge from rehabilitation centres (Coghlan et al., 1980; Hahn, 1970; Kaplan et al., 1973; Mikelberg and Reid, 1981; Rosman and Spira, 1974; Sposito et al., 1984). The non-usage rate was from $32 \%$ for $59 \%$ from previous studies (Coghlan et al., 1980; Mikelberg and Reid, 1981; Rosman and Spira, 1974; Sposito, et al., 1984).

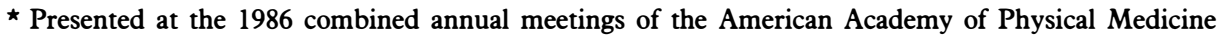
and Rehabilitation and the American Congress of Rehabilitation Medicine, Baltimore, Maryland, October 1986. 
Age, level of injury and other physical factors are considered important variables in determining brace usage (Chantraine et al., 1984; Coghlan et al., 1980; Dinken, 1951; Fisher and Gullickson, 1978; Gordon, 1956; Hahn, 1970; Hussey and Stauffer, 1973; Rosman and Spira, 1974). However, the contribution of social factors has not been well addressed.

This study was planned to determine the use of braces in SCI in a veteran's population and the physical and social factors influencing it.

\section{Methods}

A list of 250 SCI patients admitted to the Long Beach SCI Service from January 1978 to December 1984 who have been issued leg braces was obtained from the Prosthetic Service. A letter questionnaire concerning demographic data, home situation, work status, social activities, sports participation, status in activities of daily living (ADL), medical status and ambulation was sent to these patients.

A follow-up telephone survey was also carried out in some cases in order to complete the required information. The medical records were additionally reviewed to obtain the medical information as necessary. At the time of this study, all patients had had their braces prescribed for more than 1 year.

The functional levels of ambulation were divided into four categories according to Rancho Los Amigos Hospital's criteria (Hoffer et al., 1973; Hussey and Stauffer, 1973): community ambulation, household ambulation, non-functional ambulation (or exercise ambulation) and non-ambulation.

\section{Results}

Over 100 questionnaires were returned without responses due either to change of address or death of the patient. There were only 73 responses deemed to be complete and acceptable. This sample size was considered appropriately representative for all 250 patients, based on the analysis of demographic data, medical and social status. All were male veterans with an average age of 53.4 years. The average duration between onset of SCI and date of survey was 22 months

Table I Status of spinal cord injury vs type of brace

\begin{tabular}{|c|c|c|c|c|}
\hline Level of injury & Degree & $\begin{array}{l}\text { Knee-ankle-foot } \\
\text { orthosis }\end{array}$ & $\begin{array}{l}\text { Ankle-foot } \\
\text { orthosis }\end{array}$ & Total \\
\hline \multirow[t]{3}{*}{ Thoracic level } & Complete & 39 & 0 & 39 \\
\hline & Incomplete & 17 & 5 & 22 \\
\hline & Both & 56 & 5 & 61 \\
\hline \multirow{3}{*}{ Lumbar level } & Complete & 1 & 1 & 2 \\
\hline & Incomplete & 5 & 5 & 10 \\
\hline & Both & 6 & 6 & 12 \\
\hline \multirow[t]{3}{*}{ Total cases } & Complete & 40 & 1 & 41 \\
\hline & Incomplete & 22 & 10 & 32 \\
\hline & Both & 62 & 11 & 73 \\
\hline
\end{tabular}

(range 13-74). Table I shows the level of SCI and the type of brace prescribed. Based on medical record reviews, all patients were found to have received 
comprehensive rehabilitation programmes including ambulation training. One of the common reasons of brace prescription was high motivation. All 73 patients were able to walk with the brace, at least for exercise ambulation af ter completion of the rehabilitation programme (Table II).

\begin{tabular}{lcc} 
Table II Status of ambulation & \\
\hline Walkers & $\begin{array}{c}\text { At the time when } \\
\text { rehabilitation } \\
\text { programme completed }\end{array}$ & $\begin{array}{c}\text { At the } \\
\text { time of } \\
\text { survey }\end{array}$ \\
\hline Community ambulation & 15 & 5 \\
Household ambulation & 38 & 6 \\
Exercise ambulation & 20 & 5 \\
Subtotal & 73 & 16 \\
\hline
\end{tabular}

There were only $16(22 \%)$ patients who were still using their braces for ambulation at the time of this survey. All of them were below the T9 level. The remaining $57(78 \%)$ patients were completely wheelchair-dependent, and 13 occasionally used braces only for standing. Nine of the 16 ambulatory subjects had an injury at the thoracic level 2 with complete and 7 with incomplete lesions. The other 7 subjects had an injury at the lumbar level, 1 being complete and 6 incomplete. As is shown in Table II, among the 16 ambulators, 5 (7\% of all) were community ambulators, 6 were household ambulators, and 5 were exercise ambulators. The average age of the ambulatory group was 48.5 (range 26-60) and for the non-ambulators was 54.8 (range 31-72). Based on the student t-test the average age of the non-ambulatory subjects was significantly higher than that of the ambulatory subjects. The average length of initial hospitalisation after injury was not significantly different between the ambulatory and non-ambulatory groups. The time between onset of injury and date of survey was also not significantly different between these two groups.

Eight $(14 \%)$ of the 57 non-ambulators discontinued usage of the brace for ambulation within 6 months after complete rehabilitation training; 42 (74\%) discontinued usage between 6 and 12 months, and the remaining 7 patients discontinued usage between 1 and 3 years.

As is shown in Table III, some other possible aetiological factors which might cause the inability to ambulate were analysed with the Chi-square test. The behaviour of discontinuing the use of the issued lower extremity braces was not related to marital status, educational level, employment status, living arrangements, social activities and sports participation $(p>0 \cdot 1)$. It was, however, significantly related to the level of injury ( $p<0.001)$, severity of injury $(p<0.001)$, medical complications $(p<0.01)$ and the level of dependence on ADL at the time of the survey $(\mathrm{p}<0 \cdot 01)$.

Further analysis of the subjective reasons that caused the non-walker to give up ambulation with the brace revealed that difficulty and inconvenience were the major reasons, followed by medical problems (Table IV). 
Table III Correlation between status of ambulation and some etiological factors

\begin{tabular}{|c|c|c|c|}
\hline Factors & Chi-square & Degrees of Freedom & $P$ value \\
\hline $\begin{array}{l}\text { Level of injury } \\
\text { (Thoracic vs lumbar) }\end{array}$ & $11 \cdot 13$ & 1 & $<0.001$ \\
\hline $\begin{array}{l}\text { Degree of injury } \\
\text { (Complete vs incomplete) }\end{array}$ & $11 \cdot 65$ & 1 & $<0.001$ \\
\hline $\begin{array}{l}\text { Marital status } \\
\text { (Married vs unmarried) }\end{array}$ & $1 \cdot 01$ & 1 & $>0.3$ \\
\hline $\begin{array}{l}\text { Educational level } \\
\text { (College/high school/elementary) }\end{array}$ & 0.60 & 2 & $>0.8$ \\
\hline $\begin{array}{l}\text { Employment status } \\
\text { (Employed vs unemployed) }\end{array}$ & $1 \cdot 58$ & 1 & $>0 \cdot 2$ \\
\hline $\begin{array}{l}\text { Living arrangement } \\
\text { (Alone vs with other/s) }\end{array}$ & $1 \cdot 29$ & 1 & $>0 \cdot 2$ \\
\hline $\begin{array}{l}\text { Social activities } \\
\text { (Frequent vs rare) }\end{array}$ & $3 \cdot 17$ & 1 & $>0 \cdot 1$ \\
\hline $\begin{array}{l}\text { Sports participation } \\
\text { (Yes vs no) }\end{array}$ & 082 & 1 & $>0 \cdot 3$ \\
\hline $\begin{array}{l}\text { Medical problems } \\
\text { (Yes vs no) }\end{array}$ & $8 \cdot 17$ & 1 & $<0.01$ \\
\hline $\begin{array}{l}\text { Dependency on ADL } \\
\text { (Dependent vs independent) }\end{array}$ & $7 \cdot 73$ & 1 & $<0.01$ \\
\hline
\end{tabular}

Table IV Subjective reasons for non-usage of braces

\begin{tabular}{lc}
\hline Subjective reasons & Number of subjects \\
\hline Too slow, too hard, too unsafe & 20 \\
Not practical & 17 \\
Too weak & 12 \\
Broken leg/hip & 2 \\
Leg amputations & 3 \\
Muscle spasms & 3 \\
\hline Total & 57 \\
\hline
\end{tabular}

\section{Discussion}

From this retrospective follow-up study we found a higher frequency of non-usage of leg braces issued to SCI patients in a veteran's population than that reported in other studies (Coghlan et al., 1980; Hahn, 1970; Kaplan et al., 1973; Mikelberg and Reid, 1981; Rosman and Spira, 1974; Sposito et al., 1984).

The level and severity of SCI are important factors which determine the ability of functional ambulation, and thus may affect the final outcome of brace usage. Long and Lawton (1955) suggested that only exceptional patients with levels of injury above T12 could obtain any form of functionally significant ambulation, and that independent ambulation even with equipment could be achieved only by patients with injuries below the $\mathrm{L} 4$ level. This had been further supported by the later studies (Coghlan et al., 1980; Rosman and Spira, 1974; Sposito et al., 1984). In our study, no patients with lesions at $\mathrm{T} 9$ or higher would use braces continuously 
after discharge. The energy cost of ambulation for paraplegics is related to the level of the lesion, and is extremely high at the level higher than T12 (Chantraine et al., 1984; Fisher and Gullickson, 1978; Gordon, 1956). This is probably the main reason why high level paraplegics cannot use braces for ambulation continuously.

Nativig and McAdam (1978) had successfully trained their patients with SCI at thoracic level to ambulate and climb stairs. From a 10-year follow-up study of 27 paraplegics with complete lesions (T1-T10), they found that 20 patients (74\%) were able to climb 20 stairs with crutches and 19 patients $(70 \%)$ were able to walk for $100 \mathrm{~m}$. It appeared that their patients were relatively younger than other groups, and their training programmes were much more extensive and intensive.

As in previous studies (Coghlan et al., 1980; Dinken, 1951; Gordon, 1956), we found that age, physical status (medical problems) and ADL level were related to the usage of braces. The high energy expenditure of paraplegic ambulation does not allow the aged and sick subjects to sustain this high cardiopulmonary stress. For patients needing assistance in ADL, the brace donning and undonning might depend on the help from another individual. It would not be practical for those who live alone to ambulate with braces if they are not independent in ADL.

From previous studies, the most common reason given by those non-users was that ambulation with braces is 'too slow, too difficult to too unsafe' (Coghlan et al., 1980; Kaplan et al., 1973; Mikelberg and Reid, 1981; Rosman and Spira, 1974). On the other hand, the two most common reasons stated for using and receiving benefit from the braces were 'means of physical exercise' and 'improved self-image by being upright' (Coghlan et al., 1980). In our study, the reasons that made the non-walker abandon their braces were that the walking activity itself appeared to be perceived as laborious, slow and unsafe. This perception was compatible with previous studies on paraplegic energy expenditure during ambulation (Chantraine et al., 1984; Fisher and Gullickson, 1978; Gordon, 1956).

The majority of non-users interviewed felt that the desire to be independently walking with braces during their initial rehabilitation stage was psychologically reinforcing. However, the motivation to continue using the braces appeared to wane between 6 months to 1 year. The more severely impaired patients who are not realistic candidates for brace ambulation may eventually have a more positive attitude toward wheelchair ambulation as they approach discharge status (Antler et al., 1969).

It was suggested that the upright position was important to prevent complications including osteoporosis, pressure sores, spasticity, and urinary complications (Abramson, 1949; Dinken, 1951; Hahn, 1970; Nativig and McAdam, 1978). However, if the only purpose is to maintain an upright position (standing training), a pair of posterior splints would be preferred over expensive leg braces (Rosman and Spira, 1974).

Based on the results from our study, patients who are well motivated, less than 60 years old, with a level of injury at or below T9 or with incomplete injury at any level, without serious medical problems, and independent in ADL should be considered for ambulation training with braces. If braces are issued for ambulation, the patient's usage should be reinforced at least every 6 months after discharge from the Rehabilitation Centre. 


\section{Acknowledgements}

We wish to thank Dr Robert Thompson, Dr Jerome Tobis and Dr Jen Yu for their critical reading of this manuscript. We also wish to thank Phyllis Wood for the preparation of this manuscript.

\section{References}

ABRamson AS 1949 Principles of bracing in rehabilitation of Paraplegia. Bulletin of the Hospital for Foint Diseases Orthopaedic Institute 10:175-182.

Antler L, Lee MHM, Zaretsy HJH, Peznic DPH, Halberstam JL 1969 Attitude of rehabilitation patients toward the wheelchair. Fournal of Psychology 73:45-52.

Chantraine A, CrielaArd JM, ONkelink A, Pirnay F 1984 Energy expenditure of ambulation in paraplegics. Effects of long term use of bracing. Paraplegia 22:173-181.

Coghlan JK, Robinson CE, NEwMARCh B, JACKSON G 1980 Lower extremity bracing in paraplegia A follow-up study. Paraplegia 18:25-32.

DINKEN H 1951 Physical treatment and rehabilitation of paraplegic patient. FAMA 146:232-234.

EDBERG E 1967 Paralytic disfunction IV. Bracing for patients with traumatic paraplegia. Physical Therapy 47:818-823.

Fisher SV, GULLICKSON G JR 1978 Energy cost of ambulation in health and disability: A literature review. Archives of Physical Medicine and Rehabilitation 59:124-133.

GORDON EE 1956 Physiological approach to ambulation in paraplegia. FAMA 161:686-688.

HAHN HR 1970 Lower extremity bracing in paraplegics with usage follow-up. Paraplegia 8:147-153.

Hoffer MM, Feiwell E, Perry R, Perry J, Bonnett C 1973 Functional ambulation in patients with myelomeningocele. Fournal of Bone and foint Surgery 55(A):137-148.

HUSSY AW, STAUFFER ES 1973 Spinal cord injury. Requirements for ambulation. Archives of Physical Medicine and Rehabilitation 54:544-547.

KAPLAN LI, BRYNBAUM BB, RuSK HA, AMASTAIS T 1973 A reappraisal of braces and other mechanical aids in patients with spinal cord dysfunction: Results of a follow-up study. Archives of Physical Medicine and Rehabilitation 47:393-406.

KENT H 1958 Results in spinal cord injuries with early physical medicine and rehabilitation. FournalOklahoma State Medical Association 51:402-405.

LoNG C II, LAWTON B 1955 Functional significance of spinal cord lesion level. Archives of Physical Medicine and Rehabilitation 36:249-255.

MikelbeRg R, REID S 1981 Spinal cord lesions and lower extremity bracing: An overview and followup study. Paraplegia 19:379-385.

MUNRo D 1951 Two-year end results in total rehabilitation of veterans with spinal cord and cauda equina injuries. New England Fournal of Medicine 242:9-16, 1951.

MUNRO D 1954 Rehabilitation of patients totally paralyzed below waist with special reference to making them ambulatory and capable of earning their own livings. New England Fournal of Medicine 250:4-14.

Nativig H, MCAdam R 1978 Ambulation without wheelchairs for paraplegics with complete lesions. Paraplegia 16:142-146.

Rosman N, SPIRA E 1974 Paraplegic use of walking braces: Survey. Archives of Physical Medicine Rehabilitation 55:310-314.

SPOSITO MMM, CASALIS MEP, FERRARETTO I 1984 Follow-up of paraplegic patients after comprehensive rehabilitation. Paraplegia 22:373-378. 